\title{
THE COMMUNICATIVE RELEVANCE IN FICTIONAL DISCOURSE
}

\author{
Elena Godoy* \\ Rodrigo Bueno Ferreira** \\ Universidade Federal do Paraná \\ Curitiba, Brasil
}

\begin{abstract}
Searle (1975) evidenced two programmatic questions about the logic of fictional discourse: why evolution would have selected fiction as a cross-cultural behavior and what enables an author to use words literally without committing to their literal meanings in fictional communication. Ferreira (in press) argues that part of the problem lies on a Searle's conception that by violating the logical rules of assertive sentences, the fictional communication constitutes itself as parasitic ordinary language. Alternatively, this paper discusses the fictional model of communication by relevance theory (Sperber, Wilson 1995), showing that ordinary communication and fictional discourse are second-order representations or metarepresentations.
\end{abstract}

Keywords: Fictional Discourse.Communication. Theory of Mind. Metarepresentation. Relevance.

It is quite possible — overwhelmingly probable, one might guess - that we will always learn more about human life and human personality from novels than from scientific psychology.

Noam Chomsky (1987, p. 159)

\section{INTRODUCTION - THE CONTRIBUTION OF SEARLE 1}

In his work "The Logical Status of Fictional Discourse," the philosopher John Searle (1975) showed a viable logical treatment for fictional discourse, greatly contributing to the formulation of two questions to be answered by research about fiction programmatically. As the review made by the cognitive anthropologist Pascal Boyer (2007) stated, both issues raised by Searle remain obscure to science and can be presented as follows:

a) One concerns the motivation for literary fiction: what evolutionary scenarios would have led humans to obtain pleasure in fictional content?

\footnotetext{
* Associate professor in undergraduate and graduate courses in Foreign Languages and Linguistics at Federal University of Paraná, UFPR, Brazil. PhD in Linguistics at the State University of Campinas, UNICAMP, Brazil. Leader of the Language and Culture Research Group (UFPR/CNPq). E-mail: elenag@ufpr.br.

** PhD student of the Graduate Program in Linguistics at Federal University of Paraná, UFPR, Brazil. Member of Language and Culture Research Group (UFPR/CNPq). E-mail: ruod_rik@ymail.com.

${ }^{1}$ We thank Otavio Koch and Fabio Mesquita for helping us with the English version of this text.
} 
b) The other is the classic reference dilemma: how to activate the standard knowledge in order to make sense of fictional situations and processes, considering that fiction requires both the suspension and the preservation of standard assumptions about the world?

The present paper is limited to the discussion of Searle's second interrogative, 'about what enables an author to use words literally without committing to their literal meanings' to use the words of the author himself. Searle's cogitation occurs in the context of the emergence of two contrasting perspectives: on the one hand, strict logics has sought tools for the formalization of semantic elements of sentences passed in works of fiction; on the other hand, literary criticism has advanced in its statement of how fictional narratives could be interpreted in various ways.

In the tradition of logics, narrative fiction has intrigued many scholars of meaning, especially in view of the conjecture that fictional sentences could be interpreted semantically. Following the influential work of Frege (1892), in which the author suggests that fictional sentences could not be discussed in terms of truth conditions, the semantic studies were challenged to overcome the idea that language comprehension presupposes referential realism. The work of Frege suggested that in sentences like "fast asleep Odysseus has landed in Ithaca" Odysseus has a sense, but does not refer to an entity in the world, and is therefore devoid of denotation. Consequently, Frege's conception contradicted a basic intuition about the semantic competence of speakers: if entities without reference, said to be not denotative, are not subject to vericonditional evaluation, how could the speakers understand trivial information as "Odysseus is a Greek hero," "Odysseus is the husband of Penelope," or "Ulysses is father of Telemachus?"

The tradition of literary critics, in turn, followed the then emerging poststructuralist thought, going towards to today's widespread idea that "the study of literature as an objective category should be abandoned" (EAGLETON, 1996). The assertion of the literary theorist Terry Eagleton regards the possibility that anything can both be and cease to be literature. Therefore, ultimately, this conception derails the understanding of literature as a stable and well-defined entity. Some types of fiction can be considered literature, while others cannot be, and while part of literature may be fictional, some may not be. Therefore, due to the difficulty to define historical truth and artistic truth, the distinction between 'fact and fiction' does not seem to be helpful.

Similarly, Searle (1975) said it was not possible to arrive at a systematic analysis of the literature due to the lack of a feature or even a set of common characteristics in all literary works. Citing the terminology of Wittgenstein, literature constitutes a notion of family resemblances. Even before Eagleton, Searle had commented that some works of fiction are literature, some are not, and that, although most literary works are fictional, many of the narratives that literature registered are not. Therefore, it would fall upon readers to decide whether a work is literature or not, while the author would have to decide whether the work is fictional.

However, observing both the tradition of logic and the tradition of literary critics, Searle found it helpful to distinguish literary discourse and fictional discourse. His initial argument was that to consider "the Bible as literature" indicated a theologically 
neutral attitude, but "the Bible as fiction" was biased. From this, based on the theory of speech acts (AUSTIN, 1962), Searle proposed that speaking or writing in a certain language meant performing "illocutionary acts." These acts include making questions, statements, exclamations, using the imperative, making promises, apologizing, thanking, etc. There came to be, then, the postulate that fictional sentences resulted from deceptive illocutions.

Thus, for Searle, the question "how is the pretense done?" became essential. In response, the author proposed the thesis that a general feature of pretense is you can pretend to perform an action of higher order (complex) performing actions (less complex) of lower order. This was that one can pretend to hit someone performing arm and fist movements characteristic of hitting someone. While the action of beating is fake, the movement of the arm and wrist is real. Similar to children's ability to pretend to drive a parked car-sitting in the driver's seat, turning the steering wheel, changing gears, etc. - the author of a fictional narrative pretends to perform illocutionary acts by uttering, or writing sentences.

\section{FROM SEARLE TO GRICE}

When conceiving fictional sentences as illocutionary acts, Searle proposed that feigned illocutions are made possible by the existence of a set of conventions that suspend the normal operation of the rules relating illocutionary acts and the world. That is because there should be a systematic set of relations between the meaning of words and phrases we utter with the illocutionary acts we perform by uttering those words and phrases.

When presuming the systematic relationship between the meaning of uttered words and performed speech acts, Searle held that the rules that correlate words (or phrases) with the world, establishing connections between language and reality, were violated by a set of extra linguistic conventions. Thus, the conventions of fictional discourse could be thought as a set of conventions that break the links between language and the world, no longer forming the rules of meaning, components of the semantic competence of the speaker.

Consequently, such conventions would not be rules of meaning, nor would the language be on par with the illocutionary linguistic usage, instead being parasitic to it. Thus, the non-literal meaning of words could only be explained in terms of suspension of the standard workings of language, conditioning the fictional discourse as a parasite of ordinary language.

This approach, however, is objectionable. It precipitates the linguistic conception in which its literal use remains paired with the world, while fictional communication would disrupt said pairing. Both literal language can be not paired with the world, as non-literal can be paired. Furthermore, from this perspective, language ceases to be a tool for the ontological expressiveness and ends up characterized as two separate ontologies, one realistic and one fictional. 
Another contestation to the idea that the value of fictionality rests in the difference between the language it utilizes and the one that we use in daily communication was exposed by Candria (2011). Candria argued that this difference is unsustainable due to the abundance of elements of narrative fiction in communicative situations on a day-today basis. In summary, the fictional language use is not autonomous, with no unique linguistic uses of fiction that cannot be also exploited in ordinary language.

Still, Searle provided a key idea for understanding fictional discourse, providing a new answer in due course. The key was given through the explanation that pretending is an intentional verb, the type of verb that integrates in itself the concept of intention, making it not possible to say that you could pretend to do something without the intention of doing so. Criteria to determine whether a work is fictional or not were then understood as arising from the author's intentions, since in principle there would be "no textual property, syntactic or semantic, that will identify a text as a work of fiction" (SEARLE, 1975, p. 325).

In parallel with Searle's publication, Paul Grice (1975) published his influential theory of implicature in "Logic and conversation." Before, in "Meaning" (1957), Grice had inaugurated the notion of intentionality in the field of language philosophy and linguistic pragmatics, changing the focus of the research to those psychological processes which guide the speaker in their communicative interactions, rather than the meaning of sentences. Grice found that the divergence between the logicians and discourse theoreticians, like those who pored over the literature, derived from the distinction not observed until then between what is said and what is conveyed. The asymmetry between what a speaker intended to communicate and the meaning of the sentence used for the expression of his intention became apparent.

The progress obtained from Grice promoted the observation of a secondary characteristic in linguistic studies up to then. Depending on the purpose of the survey, among the main constituents of language, their purposive, propositional and syntactic properties can be mentioned. Language is purposive because there is a definite intention to carry out something for someone else in human speech, altering the behavior of this person; it is syntactic because of the fact that an utterance is the result of an internal organization, structure and coherence; and propositional because it conveys information (CHOMSKY, 1968, p. 60).

Searle's explanation, from the perspective of speech acts, has as its background the propositional property of the language, enclosing the linguistic communication in semantic terms of truth-value. Because fictional communication presents itself as a problem for a referential linguistic theory, therefore it will present problems for the referential correlation provided in speech acts theory.

Thus, the communicative question about what enables an author to use words literally without committing to their literal meanings became open in terms of the purposive characteristic of language, as per the Chomsky's definition. The purposive function developed from the recognition of the fact that the model code of language was not sufficient for communicative research, needing to be complemented by an inferential model. In this manner, the Gricean approach allowed for a conception in which the interpretation of speech acts could be made easy through inferential and implicaturial complementation. 
Still, at least two difficulties remained in the study of the fictional in the Gricean model. The first is that the inferential model was absorbed into the general framework of the theory of speech acts, so while to Grice the role of inference was fundamental to communication, in speech acts theory it was subordinate to the literal meaning. As a result, inferring was adjusted to the communicative codes pattern, its function being then understood as a mechanism that took the speech act with problematic sentences and translated them to a more appropriate propositional form (WALSH, 2007).

The other difficulty is that different narrative forms are quintessentially communicative structures that violate Grice's assumptions, most analysis of narrative genres pointing to the constant breaking of Grice's maxims (FERREIRA, 2009). Regarding the Maxim of Quality, fiction is not intentionally meant to be interpreted as literally true. Regarding the Maxim of Quantity, fiction expresses an excessive amount of information, as in the case of narrative descriptions, or insufficient information, as in the genres of suspense. Regarding the Maxim of Manner, fiction is generally indiscriminately obscure, ambiguous, wordy and cluttered. As Tooby and Cosmides (2001) heeded, Gricean restrictions to achieve efficiency in communication are radically violated in episodes of fictional communication. These observations seem to drive a pragmaticist towards following Grice's theory to question whether, after all, the only maxim not violable in fictional communication, and in general, would be the Maxim of Relation (Relevance), and, if not violated, how to explain the fictional discourse in terms of relevance.

\section{FROM GRICE TO RELEVANCE THEORY}

By separating from the semiotic paradigm of linguistic coding, relevance theory was developed under the strong assumption that inference is not a complementary component of communication, but its core. At the expense of the evolutionary development of human cognition, natural selection would have directed the increase of efficiency to three levels: the perceptual mechanisms that automatically tend to select potentially relevant stimuli; the mechanisms of memory retrieval, which automatically tend to activate potential assumptions; and the inferential mechanisms, which tend to more efficient processing of input and memory stimulus.

According to the definition of Mercier and Sperber (2011), inference is the production of new mental representations based on representations made previously. Examples of inferences can be noticed in the production of new beliefs based on a prior belief, composing the basis of any cognitive system. In other words, an inferential process is an output of a representation that necessarily or probabilistically already had a representational input.

The function of an inferential process is to enhance and correct the information available to cognition. Intuitive inferences made by human beings are not just about common objects and events, but also operations on the representations of such objects or events, i.e., a representation of higher order: representations of representations. The ability to represent representations by inferential procedure is a metarepresentational 
capacity. Humans use this expertise for intuitive inferential calculations, aiming at understanding themselves and others, also having a mechanism to represent the verbal representations and make intuitive inferences about them. This pragmatic mechanism is essential for understanding the meaning contextually stated.

The metarepresentative capacity is also called 'social intelligence' and/or 'Machiavellian,' being treated as a synonym of 'mind reading,' 'natural psychology,' 'folk psychology,' 'intentional stance' or theory of mind (ToM). Its definition is the ability to assign a full range of mental states to others as well as to yourself, using such attributions to predict and understand behavior. This idea originates from studies in primatology (PREMACK; WOODRUFF, 1978), which demonstrated that the ability to make inferences about what other people believe in a given situation can predict what they will do, clearly constituting a crucial component of social skills.

Since then, this concept has been used by psychologists and philosophers to describe our ability to explain behavior in terms of underlying thoughts, feelings, desires and intentions. We attribute mental states to ourselves and to others all the time, for instance, when someone asks for a glass of water and we deduce that he is thirsty. This example can demonstrate how the attributions can be often incorrect: the glass of water could serve to take some pill. Still, ToM is the standard means by which we act and live in our social environment (ZUNSHINE, 2008).

What the comprehension of ToM does to contribute to the fictional studies is that it seems to constitute a primordial stage of cognition, so that high cognitive levels implicate on the use of the thought process to simulate activities, actions and consequences. Foley (1995) gives the following example: 'what would happen if I threatened someone?' The thought came to constitute an apparatus by which the consequences could be staged without the need to take the risk involved in real action; by imagining myself making a threat, I can perceive the danger, in case the opponent has double my strength, or my chances of escape, in case I am faster.

The same representative capacity that supports the inferential procedure also supports the communicative procedure, allowing, in some measure, the prediction and manipulation of mental states of others (WILSON, 2000). Therefore, relevance theory predicts that the recognition of intentions is central to communication. In relevancetheoretic terms, there are two layers of intention in an overtly intentional communication. The first, the "informative intention," is the intention to inform an audience of something; the second, the "communicative intention," is the intention to inform an informative intention to an audience (SPERBER; WILSON, 1995). Therefore, the communicative intention itself is a second-order informative intention.

Similarly, the fictional discourse can also be understood as a second order relation with the real world through a logic of representation: characters, events, locations, etc. (WALSH, 2007). Thus, both linguistic communication and fictional competence converge on the ability of psychological representation of the intentional states of others in a second order dimension.

The enigma of fictional communication, discussed by Searle (1975), thus obtains an alternative response in relevance-theoretic terms. As discussed by Walsh (2007), the theoretical problem posed is that if the logic of the narrative representation does not 
establish a defensible distinction between fiction and non-fiction, then the focus of theoretical attention can be shifted from the fictional narrative as a referential act to an act of communication.

In contrast to Searle's reference formulation, in a communicative framework, fictionality resides on a way to use language. The distinction in fictional discourse can be best explained in functional terms of use and context, rather than formal terms, considering that the formal qualities strongly associated with fiction do not provide the necessary and sufficient conditions for the fictional communication.

Walsh (2007) proposed that relevance arises in fictional worlds in two aspects: the first and narrower occurs in an internal dimension to the fictional world in question; the second is external, with concerns such as likelihood and relevance of fictional worlds to the reader. Both share the characteristic dimensions of incompleteness, a well-known trouble for the theory of fictional worlds: a work of fiction cannot completely specify a world, nor provide enough bases for a broad inferential process, always leaving gaps and indeterminacies in the interpretative construction of worlds.

The characteristic of incompleteness invokes the premise that one cannot consider the fictional discourse without jointly assuming a context, albeit in more explicit discursive and literal levels. This incompleteness, however, is not solved by what is possible to infer, but for what is worth inferring. In other words, the inferential reasoning does not continue when the narrative elements are no longer relevant to a specific context of interpretation.

On the possible unrestricted interpretation and inferring about irrelevant topics, Furlong (2007) suggested the importance of considering the distinction between implications and implicatures. Similar to the distinction between natural and non-natural meaning, suggested by Grice, the implications and implicatures can be explained as follows: the formation of clouds in the sky implies rain, while the rays imply danger. However, these 'implications' are not related to communicative intentions by the clouds or the rays. They are deductions resulting from the processing of information in a given context. There is no communicative act in which a tree intends to bear information, but only a phenomenon that human beings process.

Communicative acts, however, are different: they express unnatural meanings. While it may derive some implications, the fictional communication is intentionally communicative. Consequently, it does not only provide implications, but also implicatures, which are used to assume different levels of information to be retrieved to identify the communicative intent. Even in the fictional plot, it will not only provide evidence for the interpretation, but also to the context that produces this interpretation. From this point of view about the contextual function that surrounds fiction, the interpretation relies on the evidence provided explicitly by narrative elements together with a wide variety of other resources.

Thus, the fictional discourse is not likely to be treated as an object of nature, at the risk of the complete hermeneutic determination of the reader. If this occurs, what is hypothetically plausible, then the statements were treated as a natural phenomenon, rather than intentional communication. It may occur for the reader to select an opposite interpretation to the one intended by the writer, as in cases of deliberate interpretation, or "over-interpretation," to borrow a term from Eco (1992). However, in general, the 
results of this occurrence neglect the linguistic evidence, and the failure to properly identify the statement in context can result in unacceptable interpretations.

On the contrary, when deriving interpretation by linguistic and contextual assumptions, readers tend to remain in a constant inferential process, in order to assess the communicative subtleties. The greater the repertoire deposited in the encyclopedic memory of the reader, the more easily will he distinguish between characters, locations and fictional events, being able to infer, or assign the intention meant by those references.

Each utterance is a stimulus that aims to attract attention of the reader, which generates the expectation of relevance. The criterion for evaluating hypotheses about an utterance is built around this expectation. In communication, there is a precise and powerful enough expectation of relevance so that, if the reader finds an interpretation that satisfies him, that is the one which tends to be selected.

The procedure for the reader is to accept or reject the assumptions of the author as true or probably true, framing them in their cognitive repertoire as mutually shared knowledge, stored in the encyclopedic memory or recently accessed. So communication will be successful if the reader recognizes the intention of the author, whose role is to provide evidence to the intended meaning from its ostensible procedure, in addition to some responsibility on the part of the reader, for the (re)construction of interpretation.

According to Wilson (2004, lesson 3, p. 1), the relevance-theoretic comprehension procedure assumes four simple assumptions about communication:

1a. Every utterance has a variety of linguistically possible interpretations, all compatible with the decoded sentence meaning.

1b. Not all these interpretations are equally accessible to the hearer (i.e. equally likely to come to the hearer's mind) on a given occasion.

1c. Hearers are equipped with a single, very general criterion for evaluating interpretations as they occur to them, and accepting or rejecting them as hypotheses about the speaker's meaning.

1d. This criterion is powerful enough to exclude all but at most a single interpretation (or a few closely similar interpretations), so that the hearer is entitled to assume that the first hypothesis that satisfies it (if any) is the only plausible one.

Utterances show sets of assumptions (propositional, non-propositional, feelings, impressions and so on), from which the reader will recognize the desired intent. The relevance-theoretic comprehension procedure operates as if through a function of the content of the utterance, plus the context. As illustrated by Steven Pinker (1997, p. 552):

\footnotetext{
Some of the parts are anomalous at first, and in resolving the anomaly we discover for ourselves the clever ways in which the artist shaped the different parts of the medium to do the same thing at the same time. Why, we ask ourselves, did a howling wind suddenly come up? Why does the lady have a green spot on her cheek? Why is a love song talking about musical keys? In solving the puzzles, the audience is led to pay attention to an ordinarily inconspicuous part of the medium, and the desired effect is reinforced. [...] the mind reflexively interprets other people's words and gestures by doing whatever it takes to make them sensible and true. If the words are sketchy or incongruous, the mind charitably fills in missing premises or shifts to a new frame of reference in which they make sense. Without this "principle of relevance," language itself would be impossible.
} 
In the communicative framework, criteria of truth value and reference, presupposed by Searle, are subordinate to contextual criteria. Similarly, the Maxim of Quality, privileged by Grice, is subjected to the context, given that in the perspective of relevance, information will be processed by its relevance to the context, rather than by its simple truthfulness. Since the speakers intend to achieve optimal relevance, not literal truth, an assumption can be inferred as true, and the truth of an assumption need not depend on the truth encoded in an utterance or in a literal meaning.

Given that the notion of literalness is detached from any presumption of literalness in communication, an utterance can be defined as literal provided that it has the same propositional form or some similarity to the thought of the speaker. Therefore, instead of considering that the most relevant expression is always the most literal, the understanding of the fictional discourse results in an inferential process of filling the linguistic code until achieving maximum relevance. In a more specific way, the cognitive benefit can be achieved by a wide range of cognitive effects, independent of the literalness or lack thereof in the utterances. Thus, the improvement of the knowledge needed for a positive cognitive effect may be the cumulative product of many cognitive effects, many weakly manifested hypotheses, from the process of comprehension, without necessarily depending on the propositional truth as input to this process.

Criteria of truth come into the process only to the extent that the truth is a condition for the selected context. Obtaining joy from fiction can provide a vision of life itself, through some form of analogical thinking. If only the actual entries were relevant, we would have to admit fictionality as something irrelevant, consisting of utterances of little intrinsic importance, because they are not informative. However, fictionality is not understood as a problem of non-truth, but of relevance. Rather than any expectation of accuracy, the expectations of relevance are responsible for propelling the reader to seek appropriate interpretive context. Starting from a clearly false expression, evaluations of truth only come into play due to the inferential process and the generation of implicatures.

Therefore, the investment of interpretive effort in the fictional discourse requires a permanent processing effort through enrichment, modification and revaluation of the premises on the narrative. Thus, it is possible to find relevance by constructing assumptions about the behavior, intentions and desires of the characters. These assumptions do not depend on the value of literal truth, since its validity is contextual rather than referential, not excluding yet the possibility that some of the available assumptions are referential, for example, in the case of a historical novel.

Therefore, the notion of truth in fiction does not imply an ontological framework, but a contextual qualification under which assumptions provide information relating to the context of previous assumptions. Generally, the reader does not try to solve the reference of fictional utterances by knowing beforehand that, in the absence of any evidence to the contrary, the value of literal truth is of little relevance, especially because the referential resolution is not necessary so that only then co-reference will be made possible. The comprehension of the fictional narrative progresses through more hypotheses formed on the assumptions manifested previously, the relevance being guided by pragmatic inference again, without using the referential or denotative world.

A simple "once upon a time," as an opening sentence on a fictional story, achieves its effects in a relatively simple context. The inferences available from there tend to 
provide more information than the utterance itself. The development of the subsequent narrative will carry forward the investment of the interpretive effort already made, and the effects achieved by the process of relevance will provide contextual assumptions for new inferences and new derivations.

In fact, the inference will vary from reading to reading, according to the cognitive environment and the interpretive choices of each reader, since the contextual factors act on specific expectations of relevance in each case. However, in all cases there is a tendency for these expectations to be satisfied, in accordance to the preference of some inferences, since the pragmatic realization of the process is rarely rigid. Therefore, the inferential procedure does not yield better or worse interpretations necessarily, but changes them according to cognitive interests and personal valuation, culminating in cognitive benefit and increased knowledge (WILSON, 2011).

\section{CONSIDERATIONS}

Observed from the optical reference, fictional discourse provides an element somewhat "eccentric" to linguistic studies, being authentic Searle's position when he gave the fictional communication the status of parasitic to the conditions of normal language. In contrast, a pragmatic view of fictionality requires no gap between fictional discourse and ordinary communication. Fictionality can be best understood as a communicative resource, rather than an ontological category framed in some parasitic limit of language, or a boundary between different worlds.

Some communicative forms depend on coding or implicatures solvable only by successful inferences. The communicative relevance of the fictional speech, however, is obtained through deriving a variety of weaker implicatures, according to the attributive ability of the reader. As Zunshine (2006) noted, in our daily commitment to understand others, we must be content with partial and speculative interpretations, and the more different the other is from us, more speculative is the interpretation.

The knowledge offered by fiction, however, is not primarily a precise knowledge of what is (or was), but of how it can be, of how to make sense of human affairs. The incompleteness and uncertainty are interpretative aids for the training of socializing with each other. If we devoted efforts to find out what people around us are really thinking, we would become overloaded with all possible interpretations and would be unable to take any action.

Therefore, although it is not limited to the improvement of knowledge, through its communication, the fictional contents may offer different cognitive benefits, including the resolution of contextual assumptions of fictional work.

\section{REFERENCES}

AUSTIN, John Langshaw. How to Do Things with Words: The William James Lectures Delivered at Harvard University in 1955. 2nd. ed. London: Harvard University Press, 1962.

BOYER, Pascal. Cognitive Architecture of the Imagination. Proceedings of the British Academy 147, p. 239-258, 2007. 
CANDRIA, Mytha. The Value of Relevance Theory in Literary Analysis. Prosiding Seminar Nasional: Membangun masyarakat Indonesia dalam perspektif budaya, 2011. p. 197-213.

CHOMSKY, Noam. Language and Mind. New York: Harcourt Brace \& World, 1986. 1988.

Language and Problems of Knowledge: The Managua Lectures. Cambridge, Mass: MIT Press,

EAGLETON, Terry. Literary Theory: An Introduction. Oxford, Cambridge: Blackwell, 1996.

ECO, Umberto. Interpretation and Overinterpretation. Cambridge: Cambridge University Press, 1992.

FERREIRA, Rodrigo Bueno. Análise das parábolas de Cristo sob uma perspectiva pragmático-literária. Curitiba, 2009. Monograph (BA in Letters)-Letters Course, Tuiuti University of Paraná, Curitiba, 2009.

Homo Fabulans: ficcionalidade, epistemologia e pragmática. Curitiba, 2013. Dissertation

(Master's Degree in Letters)-Graduate Program in Letters, Federal University of Paraná, Curitiba, 2013.

FOLEY, Robert. Humans before Humanity. Londres: Blackwells, 1995.

FREGE, Gottlob. On Sense and Reference. In: M. Black and P. Geach (Eds.), Translations from the Philosophical Writings of Gottlob Frege, Oxford: Basil Blackwell, 1994. p. 56-78.

FURLONG, Anne. A modest proposal: Linguistics and literary studies. Canadian Journal of Applied Linguistics, v. 10, n. 3, 2007.

GRICE, Herbert Paul. Grice, P. Meaning. The Philosophical Review, 64, 1957, p. 377-88.

Logic and conversation. In: COLE, P.; MORGAN, J. (Eds.). Syntax \& Semantics 3: Speech Acts, 1975 , p. 41-58.

MERCIER, Hugo; SPERBER, Dan. Why do Humans Reason? Arguments for an Argumentative Theory. Behavioral and Brain Sciences, v. 34, p. 57-111, 2011.

PINKER, Steven. How the Mind Works. New York: Norton, 1997.

PREMACK, David; WOODRUFF, Gui. Does the Chimpanzee Have a Theory of Mind? Behavioral and Brain Sciences, v. 1, 1978, p. 515-526

SEARLE, John. The Logical Status of Fictional Discourse. New Literary History, v. 6, n. 2, 1975, p. 319 332.

SPERBER, Dan; WILSON, Deirdre. Relevance: Communication and Cognition. 2nd ed. Oxford: Blackwell, 1995. ; Relevância: Comunicação e Cognição. Lisboa: Fundação Calouste Gulbenkian, 2001. TOOBY, John; COSMIDES, Leda. Does Beauty Build Adapted Minds? Toward an Evolutionary Theory of Aesthetics, ficTion and the Arts. SubStance, Issue 94/95, v. 30, n. 1, p. 6-27, 2001.

WALSH, Richard. The Rhetoric of Fictionality: Narrative Theory and the Idea of Fiction. Columbus: The Ohio State University Press, 2007.

WILSON, Deirdre. Metarepresentation in linguistic communication. In: SPERBER, Dan. (Ed.).

Metarepresentation: A Multidisciplinary Perspective. New York: Oxford University Press, 2000. p. 411448.

Relevance and the interpretation of literary works. Londres, UCLWPL, 2011.

Pragmatic Theory. Lesson 3. Relevance: the cognitive principle. Londres, 2004. London: UCL Linguistics Dept, 2004. Available at: <htpp://www.phon.ucl.ac.uk/home/pragtheory/>. Access on: 15 March 2005.

WITTGENSTEIN, Ludwig. Investigações Filosóficas. Petrópolis: Vozes, 1998.

ZUNSHINE, Lisa. Why We Read Fiction: Theory of Mind and the Novel. Columbus: Ohio State University Press, 2006.

Theory of Mind and Fictions of Emboidied Transparency. Narrative, v. 16, n. 1, jan. 2008, p. $65-$ 
Recebido em 20/07/14. Aprovado em 07/10/14.

Título: A relevância comunicativa no discurso ficcional

Autores: Elena Godoy e Rodrigo Bueno Ferreira

Resumo: Searle (1975) evidenciou duas questões programáticas sobre a lógica do discurso ficcional: por que a evolução teria selecionado a ficção como um comportamento transcultural e o que possibilita um autor a usar as palavras literalmente sem se comprometer com seus significados literais na comunicação ficcional. Ferreira (no prelo) argumenta que parte do problema recai sobre a concepção de Searle de que, por violar as regras lógicas das sentenças assertivas, a comunicação ficcional se constitui como parasitária da linguagem ordinária. Alternativamente, este trabalho pretende analisar a comunicação ficcional pelo modelo da teoria da relevância (SPERBER; WILSON, 1995), evidenciando que a comunicação ordinária e aquela do discurso ficcional repousam sobre representações de segunda ordem ou metarrepresentações.

Palavras-chave: Discurso ficcional. Comunicação. Teoria da Mente. Metarrepresentação. Relevância.

Título: La relevancia comunicativa en el discurso ficcional

Autores: Elena Godoy y Rodrigo Bueno Ferreira

Resumen: Searle (1975) planteó dos cuestiones programáticas sobre la lógica del discurso ficcional: ¿por qué la evolución habría seleccionado la ficción como un comportamiento transcultural? y ¿qué hace posible que un autor emplee las palabras literalmente sin comprometerse con sus significados literales en la comunicación ficcional. Ferreira (en prensa) argumenta que una parte de este problema reside en la afirmación de Searle de que, por violar las reglas lógicas de las oraciones asertivas, la comunicación ficcional se constituye como parasitaria del lenguaje humano. Alternativamente, este texto se propone a analizar la comunicación ficcional de acuerdo con el modelo de la teoría de la relevancia (SPERBER; WILSON, 1995), demostrando que la comunicación ordinaria y la del discurso ficcional se fundamentan en representaciones de segunda orden, o metarrepresentaciones.

Palabras-clave: Discurso Ficcional. Comunicación. Teoría de la Mente. Metarrepresentaciones. Relevancia. 